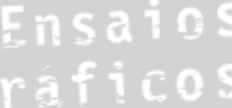

Bib I i g g

Horacio Miguel Hernán

\section{Los grupos étnicos más allá del tiempo y del espacio: hacia una antropología histórica comparada de las sociedades indígenas.}

\section{Zapata (UNR)}

NACUZZI, Lidia R., LUCAIOLI, Carina P. y NESIS, Florencia S. 2008. Pueblos nómades en un estado colonial. Chaco, Pampa, Patagonia, siglo XVIII. Buenos Aires: Editorial Antropofagia. 112 pp.

En 1924 iniciaba su recorrido esa obra que Marc Bloch tituló Los reyes taumaturgos, texto que invitaba a recorrer la historia de las creencias colectivas del milagro real y que instaba a adoptar una novel modalidad para elaborar y resignificar los problemas históricos al sostener que no habría conocimiento verdadero si no se tenía una escala de comparación. A través de sus páginas, este insigne historiador proponía comparar sociedades cercanas en el tiempo y en el espacio que se influían mutuamente, es decir, sociedades sujetas, por su proximidad, a la acción de los mismos grandes fenómenos y a la presencia de rasgos originarios comunes. Esta perspectiva de análisis trae aparejadas varias consecuencias importantes, tales como percibir las influencias mutuas que permiten avanzar más allá de una explicación estrictamente atada a los fenómenos internos de los distintos problemas, encontrar vínculos antiguos y perdurables entre las sociedades y proveer numerosas líneas posibles para nuevas investigaciones. Es evidente que la perspectiva comparada es una de las grandes promesas incumplidas de la historiografía occidental durante el siglo XX, y eso se debe, justamente, a las dificultades que implica su ejercicio, especialmente en el caso de las investigaciones regionales. El libro Pueblos nómades en un Estado Colonial. Chaco, Pampa, Patagonia, siglo XVIII, elaborado por Lidia R. Nacuzzi, Carina P. Lucaioli y Florencia S. Nesis, recupera -por así decirlo- la tradición historiográfica iniciada por Bloch pero desde la clave de la etnohistoria. El mismo explora las posibilidades de una reflexión comparativa que ponga en diálogo diversos estudios realizados en los últimos años sobre los grupos indígenas nómades que, hacia la segunda mitad del siglo XVIII, habitaban la Pampa, el norte de la Patagonia y el Chaco austral, en la 
poblaciones sedentarias. En este último término, las autoras incluyen a aquellos grupos que lo eran siguiendo sus tradiciones ancestrales, a otros que habían sido reducidos en pueblos bajo la tutela de misioneros jesuitas y a los propios hispanocriollos que se establecían en ciudades y fortines.

La delimitación de estas áreas en el escenario de una macro-región y la elección del tipo de sociedades obedecen a dos razones. En primer lugar, dar prioridad a un conjunto de temáticas que han sido objeto de inquietudes propias y, por ende, de las trayectorias de especialización investigativa de las autoras. Los recortes temáticos y los escenarios abordados se vinculan, sin duda, a los propios antecedentes de las mismas, suficientemente trabajados, argumentados y documentados en libros, artículos, capítulos de libros, ponencias, comunicaciones y papers. En efecto, el libro da muestras en su conjunto de una fructífera convivencia de la reciente producción de dos jóvenes investigadoras (Lucaioli 2005, 2009a, 2009b; Lucaioli y Nesis 2007; Nesis 2005; Nesis y Lucaioli 2005, 2006) con la reconocida trayectoria interpretativa de una experimentada académica (Nacuzzi 1991, 1992-93, 1993-94, 1998, 2000a, 2000b, 2002a, 2002b, 2005, 2006, 2008), así como de la significación que los estudios etnohistóricos encierran para la comprensión de un mundo indígena complejo, heterogéneo, dinámico y contrastante. De la misma manera, el ejercicio de síntesis se ve beneficiado con la utilización crítica y la discusión explícita de ciertas obras publicadas en los últimos años, referidas al área rioplatense o al sur sudamericano, que han contribuido, en igual sentido que estas investigadoras, a la comprensión de algunos de los fenómenos que ocurrieron en la vida social, política, económica y simbólica de las sociedades indígenas latinoamericanas del siglo XVIII. A partir de estos esfuerzos mancomunados, se observa una obra madura, rica en aristas y que puede continuar creciendo y afianzándose a partir de nuevas preguntas y nuevas síntesis (Nacuzzi 2007; Nacuzzi y Lucaioli 2008). En segundo lugar, el recorte temático obedece a la contemplación de un proceso sociohistórico común que opera como contexto de problematización: en aquella coyuntura de estructuración del nuevo Virreinato, y como resultado de un contacto de larga duración con los europeos en la, esas poblaciones originarias nómadas habían experimentado transformaciones radicales en sus formas habituales de intercambio, movilidad, adquisición de recursos económicos y explotación de los productos naturales autóctonos. A ello se sumaban las mutaciones percibidas en sus configuraciones sociopolíticas y sus nuevas estrategias de relación con los hispanocriollos que, si bien comenzaban a andar en este momento, ratificarían su tendencia y consolidarían su carácter unas décadas más tarde.

El volumen, dividido en una introducción, ocho capítulos y un apartado con bibliografía especializada, procura discutir las ideas de la semejanza cultural entre los grupos indígenas que habitaban estas regiones hasta la llegada de los europeos y de la univocidad de las estrategias en relación con los agentes colonizadores. El libro se sumerge de Ileno en estas cuestiones asumiendo uno de los principales riesgos que ello implica: la abundancia de preconceptos y de a prioris. De este modo, su segundo objetivo es mucho más ambicioso: repasar algunas de acciones y las actitudes, tanto de las poblaciones originarias como de sus colonizadores, con el ánimo de compararlas y explicar de una manera diferente, pero sobre todo más compleja, diversos temas y problemas que por muy conocidos -o tal vez sólo por muy mencionados- parecen no requerir un análisis crítico. En lo que al basamento de fuentes de primera y segunda mano se refiere, no es para nada ocioso insistir aquí en que las autoras se apartan de cualquier 
enfoque histórico positivista que ampare una lectura con pobreza de rigor. Todos los documentos que se citan, que por cierto son muy profusos y diversos en orígenes (relatos, cartas, informes, descripciones elaborados por los funcionarios, sacerdotes y viajeros, u otro tipo de personajes) y, por lo tanto, viciados de antemano por la intencionalidad de los mismos, son leídos y enmarcados con mucha atención y cuidado. De esta forma, la interpretación de la documentación logra ir más allá del polvoriento mundo de papeles, indefectiblemente mediado por lenguajes, formas narrativas y códigos de inteligibilidad de la sociedad hispanocriolla, para ir al encuentro de las propias voces y acciones de los indígenas en proposiciones referidas a sus prácticas y experiencias.

El primer capítulo, “Algunos conceptos instrumentales para el estudio de los pueblos nómades", como bien indica su título, ahonda en aquellos aspectos clave del marco teórico y conceptual, repasando las categorías que se han empleado y que continúan manejándose todavía hoy para describir y analizar el proceso de conocimiento de los grupos indígenas americanos nómades por parte de la sociedad europea. Deconstruyendo los prejuicios, sentidos comunes y problemas en los cuales se incurría por la fuerte presencia de la mirada etnocéntrica y evolutiva de los primeros observadores, historiadores y etnógrafos que analizaron los pueblos nómades, las autoras son conscientes de que algunos de tales conceptos son útiles como instrumento de análisis. Se presentan de este modo algunas formulaciones en torno a categorías como frontera, etnogénesis, mestizajes, tribu, cacicazgos y jefaturas, al mismo tiempo que se las desbroza críticamente para poder plantear un nuevo diálogo con los registros empíricos, complejizar las múltiples estrategias sociales, políticas y económicas que se pusieron en acción y, en definitiva, modificar la idea generaliza de un contacto cultural basado sólo en la violencia entre las sociedades aborígenes y los hispanocriollos.

El segundo capítulo está dedicado a un minucioso examen del "espacio geográfico y político" en el cual habitan los grupos analizados, detallando las características fundamentales desde el punto de vista espacial y ambiental de las áreas pampeano-patagónica y chaqueña. También se explaya en las formas de equipamiento político, administrativo y social que tienen lugar en tales territorios a partir de la instalación del sistema colonial. El recurso al mapa en esta sección permite una rápida visualización de los establecimientos españoles en dichos espacios (ciudades, fuertes y reducciones), al mismo tiempo que traza cartográficamente los resultados, avances y retrocesos territoriales efectivos de la política llevada a cabo por la Corona hispánica para poblar, dominar y evangelizar a los indígenas del lugar. En efecto, en todas estas regiones no colonizadas se ensayaron alternativamente los mismos tipos de dispositivos de control: los fuertes y las reducciones se ubicaban dentro de un proyecto más global que tenía por objetivos avanzar sobre los territorios indígenas, sentar precedentes del dominio español en determinados lugares y mediar los conflictos entre hispanocriollos y poblaciones nativas. Uno y otro tipo de asentamiento presentan otras dos características que los asemejaban en su función estratégica y en su dinámica funcional: una primera nota es que ambos escenarios constituyeron verdaderos enclaves fronterizos antes que una efectiva presencia política del dominio colonial; y una segunda nota, conectada con la anterior, es que la fundación y permanencia de los enclaves en el tiempo, ya fueran reducciones o fuertes, fue posible en la medida en que allí se dio una confluencia de intereses de los grupos indígenas y de las autoridades coloniales implicados. Las autoras, 
no obstante, son prudentes al destacar que la conformación geopolítica propia de estos espacios no colonizados y los grupos involucrados imprimieron perfiles especiales a cada uno de los movimientos hispanocriollos. Así lo demuestra, a guisa de ejemplo, el proceso de evangelización: mientras que en el Chaco la política reduccional estableció espacios de interacción más visibles y duraderos, donde la existencia de centros urbanos cercanos habría posibilitado el acceso a nuevos recursos y la facilidad de entablar diálogos y canalizar ciertas necesidades a partir de una relación asidua, constante y directa con los funcionarios eclesiásticos y gubernamentales; en la zona de Pampa-Patagonia, simultáneamente, el territorio controlado por los pueblos nómades era mucho más vasto y no existía el tipo de poblamiento colonial que hubiera representado barreras políticas o geográficas que los contuviera, por lo que la política reduccional fracasó o no tuvo el éxito esperado. En este último caso, las reducciones no fueron, por así decirlo, la "punta de lanza" de la conquista, por lo cual españoles y criollos se valieron de los fuertes para ocupar estas fronteras. Los fuertes, como por ejemplo el de Carmen de Patagones, se volvieron rápidamente arenas donde operaron novedosos y complejos vínculos sociales, políticos, comerciales y culturales con los aborígenes de la zona.

En el tercer capítulo, "Los grupos indígenas", las autoras presentan un recorrido por las diferentes menciones y descripciones que han realizado, desde el siglo XVIII, misioneros, funcionarios coloniales, viajeros y primeros etnógrafos sobre aquellos grupos que habitaron las regiones. De esta manera, se aprecia tanto la exagerada, aunque siempre constante, diversidad de criterios para su caracterización, como las múltiples nomenclaturas que recibieron estas poblaciones, recapituladas de manera clara y precisa al final de la sección a partir de dos cuadros de síntesis donde se vuelcan distintos autores, año de edición de sus obras y los diferentes calificativos que atribuyeron a los grupos étnicos. Ello permite mostrar cómo, tanto para la región pampeano-patagónica como para la chaqueña, los estudios etnográficos que se realizaron hasta la década de 1980 identificaron a numerosos conjuntos, aunque muchas veces se trató de una precisión meramente nominal, a la vez que establecieron una biparticipación clasificatoria que caracterizaba algunas sociedades como nómades (como los tehue/ches, abipones, tobas y mocovíes) y a otras como comunidades más sedentarias con prácticas agrícolas (como los mapuches, lules y vilelas). Este aspecto lleva a las autoras a plantear otros dos paralelismos en las investigaciones realizadas sobre las zonas propuestas. En primer lugar el hecho de que, en el devenir de los estudios etnográficos hacia los estudios históricos o etnohistóricos, en ambas regiones se pasó de la mencionada enumeración de una gran cantidad de nombres étnicos -aunque con escasas diferencias formales entre unos y otros a la hora de describir los grupos-a evitar mencionar esas subdivisiones en trabajos más recientes, que se ocupab de aspectos económicos, políticos, ceremoniales o sociales, donde la adscripción étnica parece no pesar tanto. En segundo lugar, el de que en esos mismos estudios de etnografía clásica anteriores a 1980, hubo una tendencia -en principio solamente para la región patagónica, pero que luego se reproduce con fuerza en el caso chaqueño-a considerar datos brindados por fuentes de diversos periodos y lugares como válidos para describir las poblaciones étnicas de cualquier momento del período de contacto y de cualquier lugar de los extensos paisajes considerados. 
A contratara de estas dos tradiciones, los siguientes acápites exploran problemáticas propias del tránsito intelectual de las autoras, sólido en lo heurístico y en lo interpretativo, por una "primera y segunda época", inauguradas a partir de la década de 1980. En ellas el interés de los estudios sobre las sociedades indígenas pasa nuevamente, aunque con renovados enfoques, por cuestiones "clásicas", como la economía y el comercio; las relaciones interétnicas y políticas entre grupos indígenas y "blancos"; la conformación de identidades y las transformaciones operadas en los procesos de etnogénesis y de reconfiguración cultural impulsados por el contacto con los europeos, que logran otorgar presencia histórica a estos pueblos, descriptos hasta ese momento de manera esencialista, en un continuo presente etnográfico, sin una historia posible. De esta manera, el capítulo cuarto se detiene en la descripción de los territorios y los movimientos de estos grupos. Las autoras no se limitan, por supuesto, a mostrarnos estos movimientos, de por sí interesantes, sino que tratan de explicar sus causas, estructuras y condiciones, y sus efectos sobre la economía de los mercados coloniales. Muchos lectores se sorprenderán -y otros tantos, como quien reseña y gusta observar las dinámicas sociales cartografiadas en algún formato- por el hecho de que no encontraremos mapas, planos o intentos de croquis en este capítulo que sitúen tales movimientos, pero la exposición clara, amena y sencilla permite bosquejar históricamente la ubicación y diferenciación de cada uno de los grupos, como así también los ciclos que les permitían explotar diferentes recursos desplazándose por diversos territorios a lo largo de todo el año o reuniéndose en espacios acordados previamente para intercambiar bienes, dedicarse a ciertas actividades económicas y atender ciertas cuestiones políticas y sociales, como las alianzas o los matrimonios. Las autoras, siempre atentas a las peculiaridades de las sociedades trabajadas, discuten en su análisis algunas de las teorías comúnmente aceptadas en los trabajos de este tipo. Así, por ejemplo, cuestionan las nociones acerca de que los pueblos nómades del Chaco y la Patagonia eran exclusivamente cazadores o cazadoresrecolectores, y que, por ende, la actividad predominante era la caza de grandes presas (siendo la recolección una mera actividad adicional irrelevante); de que sus movimientos estaban condiciones por el medio ambiente; de que limitaban sus prácticas económicas a la subsistencia; de que eran "salvajes• por no practicar la agricultura ni formar pueblos; o de que no programaban sus movimientos ni su vida cotidiana.

A su turno, el quinto capítulo considera la "adopción del ganado" y las "nuevas estrategias económicas", repasando los contextos económicos de los grupos que recibieron o adoptaron el caballo y los debates asociados a la crítica de la noción de complejo ecuestre o "horse complex". Aquí las autoras recuperan la noción de complementariedad para entender las relaciones económicas y enmarcan la incorporación del caballo, luego de una completa muestra de los diferentes usos y de las consecuencias (sociales, ceremoniales, políticas y económicas) que ocasionó, en un proceso histórico que involucró no sólo la adopción de otros bienes que aparecieron por el contacto con los europeos, sino también, y desde otra dirección, cambios importantes en las relaciones interétnicas, las configuraciones identitarias y las estrategias políticas, tema que será abordado en el siguiente capítulo. En efecto, el último capítulo estudia, en su primera sección, las dinámicas operadas en las formas de autoridad política que existían entre las poblaciones indígenas de Chaco, Pampa y Patagonia. A fin de dar cuenta de la complejidad de los liderazgos y de las múltiples instancias en las que eran necesarios su agencia y su rol mediador, las autoras 
distinguen los diversos rasgos que tuvo la figura del cacique en cada una de las etnias, teniendo en cuenta distintas variables como, por ejemplo, la participación de tales personajes en la conformación de las reducciones en el área del Chaco, la existencia de cacicazgos duales en el área patagónica o sus vinculaciones de diversa índole con los fuertes de la región.

La sensibilidad comprensiva de las autoras a los problemas peculiares de las regiones y de los grupos que estudian se refleja en la otra sección del capítulo seis: las interacciones interétnicas. En el cuadro de relaciones interétnicas complejas, la guerra y la diplomacia conformaron algunas de las tantas siluetas significativas de esas relaciones, resultado de los roces que la mayor proximidad generaba y de la creciente competencia por los recursos. Los malones organizados por los caciques ante lo que entendían como abusos o agresiones de los cristianos, y las campañas de represalia emprendidas por los gobiernos se sucedieron, alternados con períodos de relativa paz. Ante dicha situación, las autoridades procedieron de diferentes formas: trataron de obtener la amistad de algunos caciques con regalos y dádivas para oponerlos a los más agresivos, aprovechando para ello las rivalidades intertribales; intentaron instaurar misiones, tarea que estuvo a cargo de religiosos, que tuvieron corta existencia; buscaron fortalecer la frontera creando una organización militar basada en un sistema de fuertes, fortines y guardias y en un cuerpo de militares permanente. Guerra, alianza y reducción, entonces, fueron tres modalidades de vinculación interétnica que los diferentes actores de la sociedad hispanocriolla estimaron debían ir de la mano en tanto dispositivos centrales y concomitantes de la estrategia de sujeción de la población autóctona. Pero más allá de los reveses de estas políticas, las etnohistoriadoras encuentran que tanto en la reducción (como manera de sujeción pacífica), como en los tratados (como acuerdos de sosiego coyuntural) e inclusive en la guerra (como punición a los excesos), los caciques fueron siempre los interlocutores buscados por los agentes coloniales ya que, a cambio de la obtención de bienes y de exigir ciertos servicios y prerrogativas, facilitaban el acceso a los grupos, el conocimiento de sus políticas, las negociaciones económicas, la devolución de cautivos y los acuerdos de paz. Por su puesto, estas condiciones dependieron tanto de las aptitudes y estrategias grupales de los pueblos no sometidos aún al control del estado colonial, como de las necesidades de la población blanca, ambos resortes emplazados en ámbitos regionales y locales que les otorgaban su impronta específica.

La manera magistral con que se abordan las problemáticas muestra al enfoque comparativo como una excelente herramienta para poner a prueba la comodidad y la pertinencia de muchos de los supuestos que parecían demostrados para estos grupos; para desbrozar las similitudes y diferencias de las dinámicas sociohistóricas que involucraron a los mismos; para producir nuevas respuestas a problemas ya planteados y nuevos interrogantes que permiten revisar los siguientes tópicos: la identificación de grupos étnicos y sus nombres-rótulos; los prejuicios en torno al nomadismo y su verdadera dimensión (en regiones ora poco exploradas por los hispanocriollos, ora en donde se habían establecido un número considerable de reducciones); las nociones de territorialidad de los grupos; la existencia de cacicazgos duales; las pautas económicas de estos cazadores-recolectores; el rol de los caciques en las relaciones interétnicas; el papel de los bienes europeos en su economía; los procesos de especialización para responder a la demanda de los mercados coloniales y la complementariedad-principalmente en los aspectos 
económicos, pero también de otros tipos- entre grupos nómades y grupos sedentarios. En este último término las autoras incluyen a aquellos grupos que lo eran siguiendo sus tradiciones ancestrales, a otros que habían sido reducidos en pueblos bajo la tutela de misioneros jesuitas, y a los propios hispanocriollos que se establecían en ciudades y fortines.

Sin duda, como todo intento de síntesis, el libro que reseñamos ofrecerá en el futuro algunos caminos novedosos, problemas son resueltos, hipótesis a confirmar o a rectificar que estimularán nuevas investigaciones en la historia social, económica, política y cultural del mundo indígena suramericano del siglo XVIII. Pero además, redundará en una experiencia más que significativa para el lector, ya que este obtendrá una imagen más nítida de cómo los pueblos aborígenes tanto del norte de la Patagonia y la Pampa como del Chaco austral, aun reducidos, desarrollaron en esas condiciones una manera de vivir que se adaptaba a sus pautas anteriores -sobre todo en cuanto a movimientos- y les permitía flexibilizar la inmovilidad que hubiera supuesto la vida en un pueblo de reducción; y de cómo aquellas sociedades que no ingresaron en este tipo de situaciones y permanecieron autónomas fueron protagonistas muy activos de los contactos interétnicos, desarrollando espacios de acción y comunicación con los europeos, entrecruzando sus prácticas socioculturales e improvisando formas originales de actuar e intervenir en diversas esferas de la vida social y política, lo que los transformó en agentes no secundarios en la historia de dichas interacciones sociales. En el esfuerzo de dejar atrás viejas concepciones, de no crear nuevos mitos y de confrontar las agencias indígenas en la realidad rioplatense, Pueblos Nómades en un estado colonial... constituye un excelente comienzo. Y eso es ya decir mucho. 


\section{BIBLIOGRAFIA}

LUCAIOLI, Carina P. 2005. Los grupos abipones hacia mediados de/ siglo XVIII. Buenos Aires: Sociedad Argentina de Antropología.

. 2009a. "Alianzas y estrategias de los líderes indígenas abipones en un espacio fronterizo colonial (Chaco, siglo XVIII)". Revista Española de Antropología Americana 39 (1): 77-96.

. 2009b. “Construcción de territorios: percepciones del espacio e interacción indígena y colonial en el $\overline{C h a c o}$ austral hasta mediados del siglo XVIII". Antípoda. Revista de Antropología y Arqueología 1: 117-140.

LUCAIOLI, Carina P y NESIS, Florencia. 2007. “El ganado de los grupos abipones y mocoví en el marco de las reducciones jesuitas (1743-1767)". Andes. Antropología e Historia 18: 129-152.

NACUZZI, Lidia R. 1991. “La cuestión del nomadismo entre los tehuelches”. Memoria America. Cuadernos de Etnohistoria 1: 103-134.

1992-93. “'Nómades' versus 'sedentarios' en la Patagonia (siglos XVIII-XIX)". Cuadernos del Instituto Nacional de Antropología y Pensamiento Latinoamericano 14: 81-92.

. 1993-94. "Los cacicazgos duales en Pampa-Patagonia durante el siglo XVIII". Relaciones de la Sociedad Argentina de Antropología XIX: 135-144.

. 1998. Identidades impuestas. Tehuelches, aucas y pampas en el norte de la Patagonia. Buenos Aires: Sociedad Argentina de Antropología.

. 2000a. “El papel de los contactos intergrupales en el abastecimiento de productos en Patagonia, siglo $\overline{\mathrm{XVIII"}}$. Arqueología 10: 121-134.

. 2000b. "Estrategias sociales en una situación de contacto" In G. Boccara y S. Galindo (eds.) Lógica Mestiza en América. Temuco: Universidad de la Frontera / Instituto de Estudios Indígenas. 139-163.

. 2002a. "Los grupos, los nombres, los territorios y blancos: historia de algunos nombres étnicos". In G. Boccara (ed.) Colonización, resistencia y mestizaje en las Américas. Lima/Quito: Instituto Francés de Estudios Andinos / Abya-Yala Editores. pp. 259-289.

. 2002b. “Francisco de Viedma, un 'cacique blanco' en tierra de indios”. In L. R. Nacuzzi (comp.) Funcionarios, diplomáticos y guerreros. Miradas hacia el otro en las fronteras de pampa y Patagonia (Siglos XVIII y XIX). Buenos Aires: Sociedad Argentina de Antropología. pp. 25-64.

2005. “El queso y los gusanos en el extremo sur de América. Grupos étnicos, disputas académicas y un juicio por registro de marca". Revista de Indias LXV (234): 427-452.

. 2006. "Tratados de paz, grupos étnicos y territorios en disputa a fines del siglo XVIII". Investigaciones Sociales X (17): 435-456. 
2007. “Los grupos nómades de la Patagonia y el Chaco en el siglo XVIII: identidades, espacios, movimientos y recursos económicos ante la situación de contacto". Chungara. Revista de Antropología Chilena 39 (2): p.221-234.

2008. “Revisando y repensando el concepto de cacicazgo en las fronteras del sur de América (Pampa y Patagonia)". Revista Española de Antropología Americana 38 (2): 75-95.

NACUZZI, Lidia R y LUCAIOLI Carina P. 2008. "'y sobre las armas se concertaron las paces': explorando las rutinas de los acuerdos diplomáticos coloniales". CUHSO. Cultura - Hombre - Sociedad 15 (2): 61-74.

NESIS, Florencia. 2005. Transformaciones socioculturales entre los grupos mocoví. Siglo XVIII. Buenos Aires, Sociedad Argentina de Antropología.

NESIS, Florencia y LUCAIOLI, Carina. 2005. “Transformaciones en torno a los liderazgos abipón y mocoví (siglo XVIII)". CD Actas III Jornadas de Investigación en Antropología Social. Buenos Aires: Universidad de Buenos Aires.

2006. "El liderazgo político en un espacio de contacto: el Chaco austral en el siglo XVIII". Ponencia presentada en Jornada de Debate "Espacio y poder en el Chaco, siglos XVI-XVIII". Buenos Aires: Instituto de Historia Argentina "Dr. Emilio Ravignani” - RER/PROER. Mimeo. 